\title{
Compressed vertebrae in Atlantic salmon Salmo salar: evidence for metaplastic chondrogenesis as a skeletogenic response late in ontogeny
}

\author{
P. Eckhard Witten ${ }^{1,2, *}$, Laura Gil-Martens ${ }^{3}$, Brian K. Hall ${ }^{2}$, Ann Huysseune ${ }^{4}$, \\ Alex Obach ${ }^{3}$
}

\begin{abstract}
${ }^{1}$ University of Hamburg, Zoological Institute, Martin-Luther-King Pl. 3, 20146 Hamburg, Germany ${ }^{2}$ Department of Biology, Dalhousie University, 1355 Oxford Street, Halifax, Nova Scotia B3H 4J1, Canada ${ }^{3}$ Nutreco Aquaculture Research Centre, Sjøhagen 3, 4016 Stavanger, PO Box 48, 4001 Stavanger, Norway ${ }^{4}$ Ghent University, Vakgroep Biologie, Ledeganckstraat 35, 9000 Ghent, Belgium
\end{abstract}

\begin{abstract}
Anterior/posterior (a/p) compression of the vertebral column, referred to as 'short tails', is a recurring event in farmed Atlantic salmon. Like other skeletal deformities, the problem usually becomes evident in a late life phase, too late for preventive measures, making it difficult to understand the aetiology of the disease. We use structural, radiological, histological, and mineral analyses to study 'short tail' adult salmon and to demonstrate that the study of adult fish can provide important insights into earlier developmental processes. 'Short tails' display a/p compressed vertebrae throughout the spine, except for the first post-cranial vertebrae. The vertebral number is unaltered, but the intervertebral space is reduced and the vertebrae are shorter. Compressed vertebrae are characterized by an unchanged central part, altered vertebral end plates (straight instead of funnel-shaped), an atypical inward bending of the vertebral edges, and structural alterations in the intervertebral tissue. The spongiosa is unaffected. The growth zones of adjacent vertebrae fuse and blend towards the intervertebral space into chondrogenic tissue. This tissue produces different types of cartilage, replacing the notochord. The correspondence in location of intervertebral cartilage and deformed vertebral end plates, and the clearly delimited, unaltered, central vertebral parts suggest that the $a / p$ compression of vertebral bodies is a late developmental disorder that may be related to a metaplastic shift of osteogenic tissue into chondrogenic tissue in the vertebral growth zone. Given the lack of evidence for infections, metabolic disorders and/or genetic disorders, we propose that an altered mechanical load could have caused the transformation of the bone growth zones and the concomitant replacement of the intervertebral (notochord) tissue by cartilaginous tissues in the 'short tails' studied here. This hypothesis is supported by the role that notochord cells are known to play in spine development and in maintaining the structure of the intervertebral disk.
\end{abstract}

KEY WORDS: Notochord - Skeletal deformities · Vertebral malformations $\cdot$ Metaplasia $\cdot$ Bone Salmon $\cdot$ Chondrogenesis

\section{INTRODUCTION}

Deformities of the vertebral column in wild and farmed teleosts surface as spine curvature, as anterior/posterior $(\mathrm{a} / \mathrm{p})$ shortening of the spine, or as a combination of spine curvature and $a / p$ shortening (Gil \& Fisk 1966, McKay \& Gjerde 1986, Dedi et al.
1995, Kvellestad et al. 2000, Gavaia et al. 2002). While deformities that involve bending of the spine (lordotic, kyphotic and skoliotic malformations) might become obvious at earlier life stages, the $\mathrm{a} / \mathrm{p}$ shortening of the spine is usually much less conspicuous. Mild cases that affect only part of the vertebral column often remain undetected (unless the fish are X-rayed) or might 
be regarded as undeformed (McKay \& Gjerde 1986, Madsen et al. 2000). In Atlantic salmon Salmo salar the pronounced $\mathrm{a} / \mathrm{p}$ compression of the vertebral column results in a phenotype that is characterized by a reduced fork length (FL) and increased body height, traits that result in a deformity-related high condition factor (CF). These individuals are referred to as 'short tails' (Vågsholm \& Djupvik 1998).

The appearance of 'short tails' is a recurrent problem in salmon farming. The prevalence can vary from year to year, from region to region, and from cage to cage. Some observations suggest that the prevalence of 'short tails' follows a smolt group, with higher frequencies in groups of fast growth smolts (L. Gil-Martens pers. obs.). Typically, the deformity becomes evident in advanced life stages, at a time when it is too late for preventive measures. Late detection of the 'short tail' phenotype is one reason why it is difficult to understand the aetiology of the disease. The co-occurrence of various types of skeletal tissue alterations and the fact that alterations can occur in different regions of the spine makes it even more difficult to draw conclusions regarding possible aetiologies (McKay \& Gjerde 1986, Bæverfjord et al. 1996). Correlated malformations of bone consist of fracture and non-fracture related compression of vertebral bodies, distortion and underdevelopment of single vertebrae, alterations of the intervertebral space and fusion of vertebrae (Vågsholm \& Djupvik 1998, Kvellestad et al. 2000, Gavaia et. al 2002). Past studies on 'short tails' proposed various factors that could cause this type of skeletal malformation. Among those factors are the imbalance of vitamins or minerals, bacterial infections, treatment with antibiotics and genetic disorders (Dedi et al. 1995, Toften \& Jobling 1996, Kvellestad et al. 2000, Madsen et al. 2000, 2001). Combinations of factors have also been considered (Madsen \& Dalsgaard 1999). Other factors that can cause skeletal deformities are chemical pollution and elevated temperatures during early developmental stages (Bucke \& Watermann 1988, Vågsholm \& Djupvik 1998, Scott 2001). In commercial salmon farming, however, those data are difficult to obtain if more than one fish producer is involved in raising the salmon from eggs to adults. It is common practice for salmon farmers to buy juvenile fish from a hatchery for further rearing. Under these circumstances, each party involved in raising the fish is supposed to assure (and will do so) that the fish have been raised under the best possible conditions regarding temperature regime and water quality.

Those studying 'short tails' are usually faced with multiple symptoms (e.g. fractures, distortion, and infections at various sites), which makes it difficult to distinguish between primary and secondary causes of skeletal alterations. In contrast to previous studies, we here analyze a late-detected 'short tail' phenotype in adult salmon that displays uniform and nonregionalized vertebral $a / p$ compression. The fact that there is only one type of skeletal alteration in these fishes, which is homogeneous throughout the spine, can help to elucidate the primary cause of such alterations. The examination of uniformly deformed salmon also demonstrates that the study of adult fish can provide valuable insights into those developmental processes that lead to a 'short tail' phenotype.

\section{MATERIALS AND METHODS}

Sampling, measurements and statistics. Samples were taken in April 2002 from farmed Atlantic salmon, raised under standard commercial conditions by Marine Harvest Rogaland (Norway) from a batch in which $35 \%$ of the fish had to be downgraded because of displaying 'short tail' symptoms. Twenty fully grown (harvest weight) individuals were selected at the slaughterline: 10 undeformed and 10 deformed (downgraded) salmon ('short tails'). For each group, fish with a uniform morphology were chosen, corresponding to the individuals shown in Fig. 1. All fish were photographed and X-rayed. Weight and FL were determined to calculate the $\mathrm{CF}: \mathrm{CF}=\left[\right.$ weight $\left.(\mathrm{g}) / \mathrm{FL}\left(\mathrm{cm}^{3}\right)\right] \times 100$. Subsequently, the vertebral column was removed for morphological and histological examinations and for analysis of bone minerals (see below). Ten salmon (5 undeformed and 5 deformed) were used for morphological and histological examinations, and 10 (5 undeformed and 5 deformed) for mineral analysis. All analyses were undertaken on vertebrae located below the dorsal fin.

The number of vertebrae was determined in all individuals. The length and height of the vertebrae, and the width of the intervertebral space were obtained from 10 vertebrae per individual based on enlarged radiographs. Measurements were taken from vertebrae 16 to 20 in the abdominal region and from vertebrae 41 to 45 in the caudal region (regions of the vertebral column as defined by Gill \& Fisk 1966).

For metric data, for calculated indices (e.g. CF) and for the results of the mineral analysis we give mean values and the standard deviation. A non-parametric statistical test (Kruskal-Wallis ANOVA analysis) was used to obtain indications concerning the significance of the observed differences between undeformed and deformed fish. Significant differences are indicated by p-values lower than 0.05 . In view of the small sample size, we refrain from further statistical treatment.

Mineral analysis. Fifteen vertebrae from each fish were used for mineral analysis. The soft tissue was 
removed and the bones were cleaned with demineralized water. Subsequently, lipids were removed from the samples by rinsing the samples twice in a mixture of acetone and methanol $(1: 1, \mathrm{v} / \mathrm{v})$. The samples were then dried for $24 \mathrm{~h}$ at $105^{\circ} \mathrm{C}$, ashed at $550^{\circ} \mathrm{C}$ for $18 \mathrm{~h}$ and digested according to the AOAC method (AOAC 1995). The phosphorus content of the ash was determined colorimetrically (Taussky \& Shorr 1953); all other minerals were quantified by atomic absorption spectroscopy (AAS).

Radiology. X-rays from all fish were taken using a portable 'Mini X-ray HF80+' machine (Mini X-ray) and 'Kodak Industrex M Film Ready Pack II' (Kodak Industry). No screens for increasing the strength of the X-ray beam were used. The settings of the X-ray unit were $70 \mathrm{kV}, 15 \mathrm{~mA}, 2 \mathrm{~s}$ exposure time, and a distance of $40 \mathrm{~cm}$ between the beam source and the X-ray film was used. Radiographs were developed with Kodak chemicals according to the protocol of the manufacturer (Witten \& Hall 2002).

Maceration. For maceration, vertebrae were subjected to trypsin digestion for $48 \mathrm{~h}$ (200 mg trypsin dissolved in $30 \%$ sodium tetraborate buffer at $\mathrm{pH} 9.4$ ), subsequently treated with $1 \%$ potassium hydroxide solution for an additional $48 \mathrm{~h}$, and finally rinsed in tap water. Remaining soft tissue was removed with a brush.

Histological procedures. Vertebrae were fixed in $10 \%$ neutral buffered paraformaldehyde for $24 \mathrm{~h}$, rinsed in tap water for $24 \mathrm{~h}$, and decalcified for $72 \mathrm{~h}$ in a $10 \%$ EDTA solution buffered with $0.1 \mathrm{M}$ Tris base at $\mathrm{pH}$ 7.0. After decalcification, samples were stepwise dehydrated and embedded in Paraplast.

Serial sections $(10 \mu \mathrm{m})$ were prepared in the sagittal plane of the vertebral columns, starting at the periphery and ending in the middle plane of the vertebrae. Sections were stained with Masson's trichrome as the basic analytical procedure according to the following protocol (Witten \& Hall 2003): deparaffinized sections were stained for $10 \mathrm{~min}$ with Mayer's acid haematoxylin (Sigma MSH-32), exposed to running tap water for $10 \mathrm{~min}$ and rinsed in distilled water (distilled water was used for all following rinsing steps). Then, sections were stained with xylidene ponceau for 2 min (equal volumes of $0.5 \%$ xylidine ponceau $2 \mathrm{R}$ colour index (C.I.) No. 16150, in $1 \%$ acetic acid and $0.5 \%$ acid fuchsin C.I. No. 42685, in $1 \%$ acetic), rinsed, treated for $4 \mathrm{~min}$ with $1 \%$ phosphomolybdic acid, rinsed, and stained with light green for $90 \mathrm{~s}$ (2\% light green C.I. 42095 in $2 \%$ citric acid, diluted 1:10 with distilled water prior to use). Sections were then dehydrated in series of graded ethanol solutions, rinsed with histoclear, and finally mounted with DPX (Fluka).

Based on the stained sections, the quality of skeletal and connective tissues and cells was determined. The sections also served for the determination of possible inflammatory processes indicated by the presence of cells such as lymphocytes, granulocytes, monocytes, or macrophages (Witten et al. 1998, Kvellestad et al. 2000).

\section{RESULTS}

Deformed salmon display a shortened body axis and increased body height (Fig. 1). The average FL of deformed individuals was $44.0 \pm 3.4 \mathrm{~cm}$ compared to $67.7 \pm 6.8 \mathrm{~cm}$ in undeformed individuals. Deformed fish show an increased $\mathrm{CF}$ : $\mathrm{CF}=1.6 \pm 0.1$ compared to $\mathrm{CF}=1.1 \pm 0.1$ in undeformed fish. Counting the vertebrae revealed that the 'short tail' phenotype is not related to an altered number of vertebrae since numbers ranged from 58 to 61 in deformed fish and from 57 to 60 in undeformed fish.

The X-rays from deformed salmon display homogeneously compressed vertebral bodies throughout the vertebral column (Fig. 2). Only the first 8 or 9 postcranial vertebrae had a more or less regular shape (Fig 3). Measurements of the vertebrae of deformed and undeformed individuals reveal that the vertebrae of 'short tails' differ in length (about $47 \%$ reduction) and in height (about 18\% reduction) from vertebrae of undeformed individuals. In addition, the width of the intervertebral space in 'short tails' is reduced by about $54 \%$ (see Table 1).

Higher magnifications of radiographs highlight the morphological differences between vertebrae of deformed and undeformed salmon. Regularly shaped vertebrae have an X-shape in silhouette, whereas the vertebrae of deformed salmon show a characteristic inward bending of the vertebral edges (Fig. 4).

Histological examination of the vertebrae confirms the shape differences seen on the X-rays and reveals that structural alterations are confined to the vertebral

Table 1. Salmo salar. Average size of vertebrae $( \pm \mathrm{SD})$, obtained by measuring 10 vertebrae per individual (vertebrae 11 to 15 and 41 to 45 ). N: normal individuals; ST: 'short tails'. p-values $<0.05$ indicate that the observed differences are significant

\begin{tabular}{|lccc|}
\hline & Average $(\mathrm{mm})$ & $\pm \mathrm{SD}$ & $\mathrm{p}$-value \\
\hline Vertebral length & & & \\
$\mathrm{N}$ & 8.56 & 1.13 & 0.002 \\
$\mathrm{ST}$ & 4.50 & 0.39 & \\
Intervertebral space & & & \\
$\mathrm{N}$ & 1.01 & 0.21 & 0.003 \\
$\mathrm{ST}$ & 0.46 & 0.18 & \\
Vertebral height & & & \\
$\mathrm{N}$ & 9.22 & 1.22 & 0.030 \\
$\mathrm{ST}$ & 7.55 & \pm 0.49 & \\
\hline
\end{tabular}



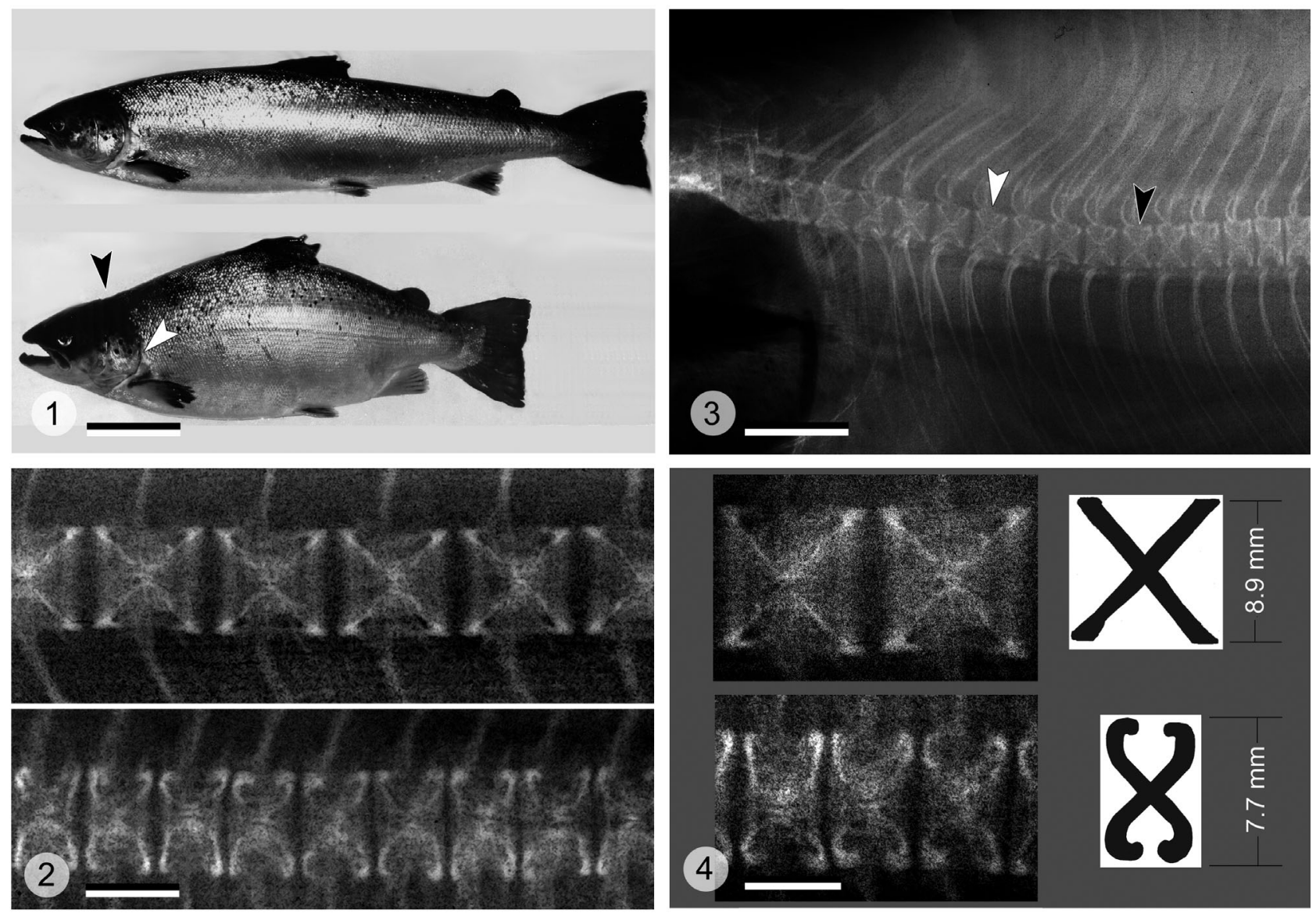

Figs. 1 to 4. Salmo salar. Fig. 1. Comparison of an undeformed adult salmon (top) and a 'short tail' salmon (bottom). 'Short tails' have a reduced fork length and increased body height. Apart from a typical indentation behind the head (black arrowhead) the deformed fish display no other significant skeletal alterations; even the operculum is apparently unchanged (white arrowhead). Scale bar $=8 \mathrm{~cm}$. Fig. 2. Vertebral columns from an undeformed fish (top) and from a 'short tail' (bottom), at the same magnification. In the 'short tail', anterior/posterior (a/p) compression of vertebral bodies is homogeneous throughout the backbone (but see Fig. 3). Apart from compression there are no signs of vertebral fusion or fracture. Scale bar $=7.5 \mathrm{~mm}$. Fig. 3. Anterior part of the vertebral column of a 'short tail'. Radiograph shows that the first 9 vertebrae are not compressed (white arrowhead). Black arrowhead points to the start of obvious signs of compression and shape alteration. Scale bar $=15 \mathrm{~mm}$. Fig. 4. Higher magnifications of undeformed (top) and a/p compressed (bottom) vertebrae displaying distinct shapes, schematically represented on the right side. Average height of compressed vertebrae is slightly less than that of non-compressed vertebrae. Figure visualizes that 2 non-compressed vertebrae roughly take the space of 3 compressed vertebrae. Scale bar $=5 \mathrm{~mm}$

end plates and the intervertebral tissue. Parasagittal sections of undeformed vertebrae show funnel-shaped end plates and notochordal tissue (surrounded by the notochord sheath) filling the intervertebral space (Fig. 5). In 'short tails', a section in the same plane shows straight vertebral end plates. The notochordal tissue and the notochordal sheath are missing. Instead the vertebral end plates are linked by cartilaginous connective tissue (synchondrosis) (Fig. 6).

Mediosagittal sections of deformed vertebrae reveal residues of the notochord and normal (funnel-like) shaped end plates, albeit limited to the central part of the vertebrae (Fig. 7). Towards the periphery of the vertebrae, the notochordal tissue is discontinuous and the shape of the vertebral end plates becomes ir- regular. Structural differences between vertebrae from undeformed and deformed fish are also visible on macerated vertebral bodies (Fig. 8). The undeformed end plate shows continuous formation of growth rings. In the deformed vertebrae, growth ring formation is discontinuous towards the periphery, corresponding to the altered pattern of bone formation and notochord replacement seen in Fig. 7. As described above (Figs. 5 \& 6), structural alterations are apparently restricted to the intervertebral space and the vertebral end plates, while the spongiosa structure in deformed and undeformed vertebrae is identical (Fig. 9). This applies also at the histological level (Fig. 10). In both groups, the spongiosa has smooth endosteal surfaces and is covered with bone lining 

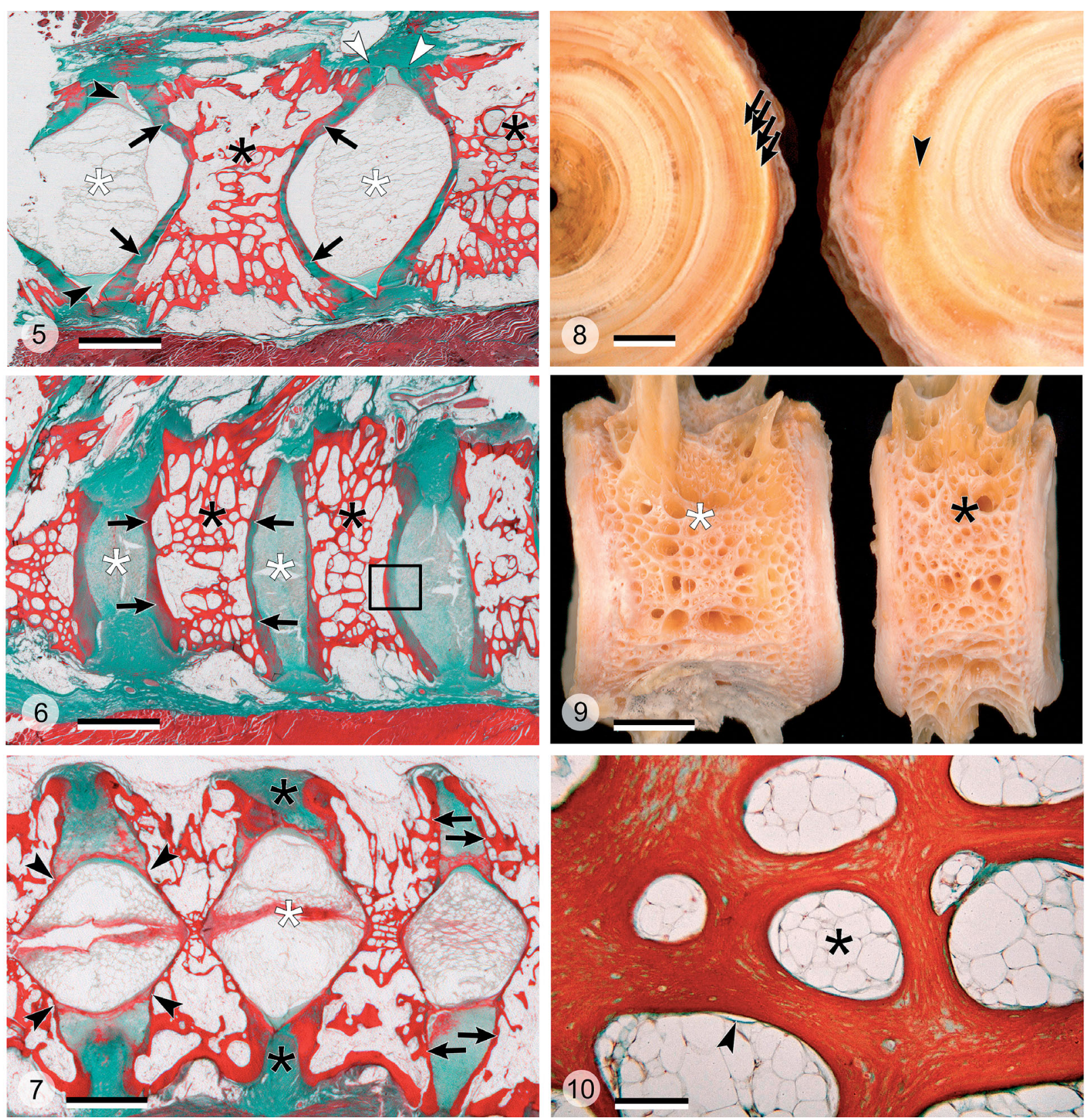

Figs. 5 to 10. Salmo salar. Fig. 5. Parasagittal section through the vertebral column of an undeformed fish, showing the spongiosa of the vertebral body (black asterisks, see also Fig. 9) and notochord tissue filling the intervertebral space (white asterisks). Notochord tissue is surrounded by a notochordal sheath (black arrowheads). Bone growth occurs in the contact area of opposing vertebral body end plates (white arrowheads). Note funnel-like shape of the vertebral body end plate (black arrows). Masson's trichrome staining; scale bar $=2.0 \mathrm{~mm}$. Fig. 6 . Parasagittal section through the vertebral column of a deformed fish. Regular spongiosa forms the vertebral body (black asterisks, see also Figs. 9 \& 10) but unlike in undeformed vertebrae the intervertebral space is occupied by cartilaginous tissue (white asterisks). Note that vertebral body end plates have lost their funnel-like shape (black arrows, see also Fig. 5). Box indicates area enlarged in Fig. 14. Masson's trichome staining; scale bar $=2.0 \mathrm{~mm}$. Fig. 7 . Vertebral column of a deformed fish: sagittal section close to the median plane. Regular funnel-like shaped vertebral end plates and notochord tissue are preserved in the centre of the structure (white asterisk). From distinct points onwards (black arrowheads), towards the periphery of the vertebrae, regular notochord tissue is completely replaced by cartilage (black asterisks). Likewise, vertebral end plates change their shape from funnel-like to straight (black arrows). Masson's trichrome staining; scale bar $=2.0 \mathrm{~mm}$. Fig. 8. Undeformed (left) and deformed (right) macerated vertebrae; view of the vertebral body end plates. Undeformed end plate $\overline{\text { shows }}$ continuous formation of growth rings (black arrows). In the deformed vertebra, growth ring formation is discontinued (black arrowhead) in correspondence to the altered pattern of bone formation and notochord replacement seen in Fig. 7. Scale bar $=1.0 \mathrm{~mm}$. Fig. 9. Lateral view of 2 macerated vertebral bodies; undeformed (left), deformed (right). Despite its severe anterior/posterior $(\mathrm{a} / \mathrm{p})$ compression, the spongiosa structure of the deformed vertebra (black asterisk) does not differ from the spongiosa structure of the undeformed vertebra (white asterisk). Scale bar $=2.0 \mathrm{~mm}$. Fig. 10. Higher magnification of the spongiosa from a deformed vertebra. Endosteal bone surfaces are smooth and covered by bone lining cells (black arrowhead). Bone marrow is filled with fat tissue (black asterisk). Bone displays no signs of fractures or enhanced bone remodelling. Spongiosa histology of undeformed vertebrae (not shown) is identical (see also Figs. 5, 6 \& 9). Masson's trichrome staining; scale bar = $100 \mu \mathrm{m}$ 

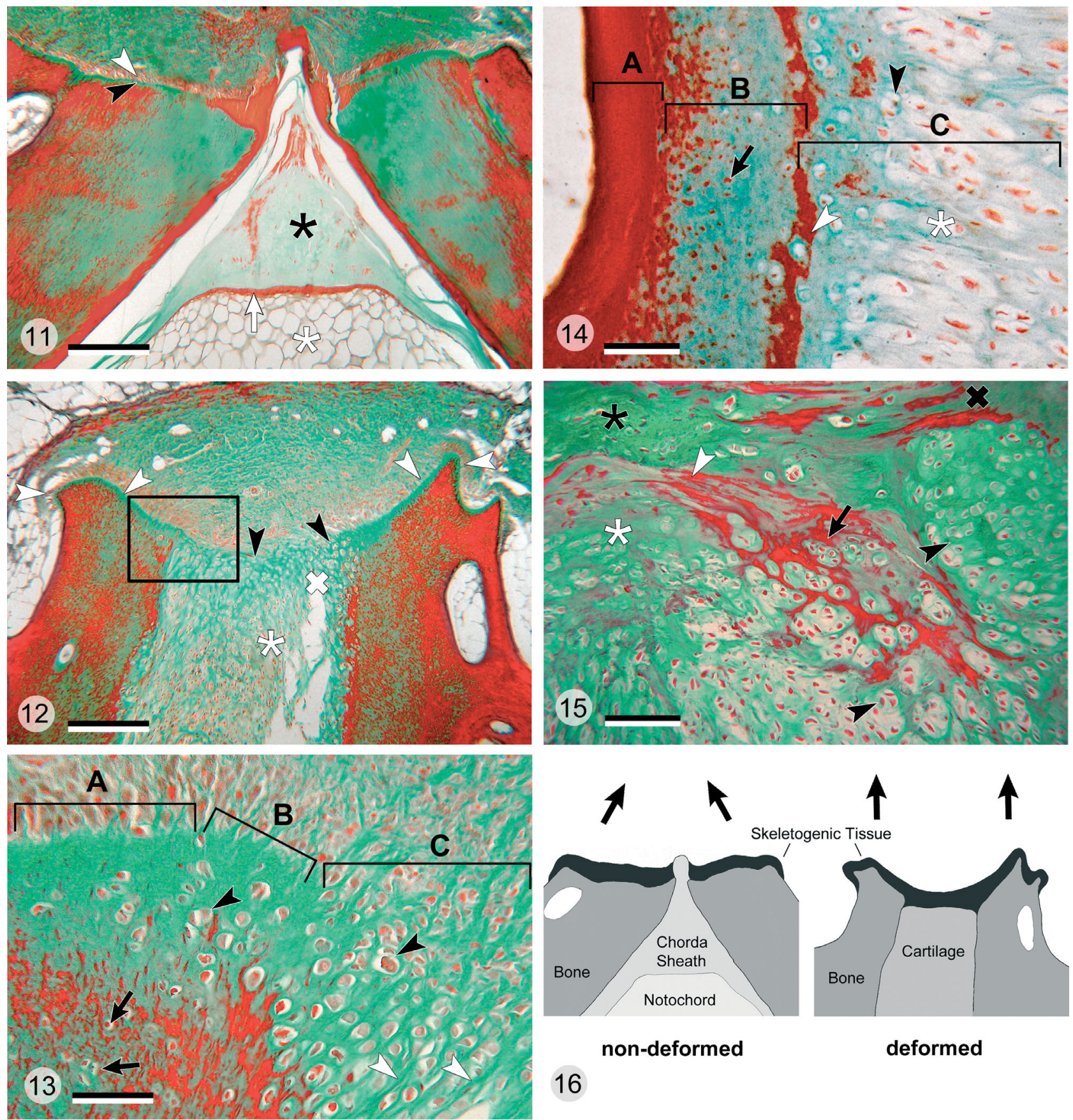

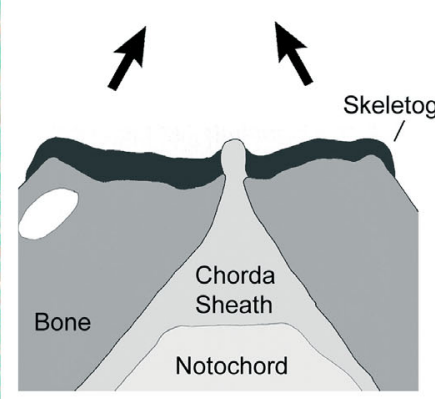

non-deformed

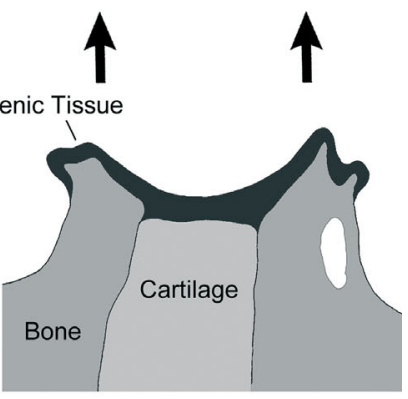

deformed

16

cells. Bone marrow spaces are filled with fat tissue. The spongiosa displays no signs of fractures or enhanced bone remodelling.

However, histological examination of the growth zones of undeformed and deformed vertebrae reveals pronounced differences (Figs. 11 \& 12). Adjacent vertebrae of undeformed fish are characterized by mirrorimage growth zones separated by the notochordal sheath. Each bone growth zone displays typical osteoblasts secreting the non-mineralized bone matrix (osteoid), which is subsequently mineralized (Fig. 11). The corresponding growth zones in deformed vertebrae display pronounced alterations (Fig. 12). The areas of bone formation extend rostrally and caudally (not seen in undeformed vertebrae). The growth zones of adjacent vertebrae fuse and blend towards the intervertebral space into chondrogenic tissue. This tissue produces hyaline cartilage and fibrocartilage that replaces the notochord (Figs. $13 \& 14)$. The different types of cartilage in the intervertebral space also show 
Figs. 11 to 16. Salmo salar. Fig. 11. Symmetrical growth zones of 2 adjacent undeformed vertebrae. Osteoblasts (white arrowhead) secrete the non-mineralized bone matrix (osteoid) (black arrowhead) that subsequently mineralizes. Space between the vertebrae is occupied by the notochord (white asterisk), notochordal epithelium (white arrow), and notochordal sheath (black asterisk). Masson's trichrome staining; scale bar $=250 \mu \mathrm{m}$. Fig. 12. Growth zones of adjacent deformed vertebrae. Osteogenic zones extend rostrally and caudally (white arrowheads) and fuse between the 2 vertebrae into a zone of chondrogenic tissue (back arrowheads). Chondrogenic tissue gives rise to cartilage (white cross) and fibrocartilage (white asterisk) replacing all tissues that belong to the notochord. Box indicates area enlarged in Fig. 13. Scale bar $=250 \mu \mathrm{m}$. Fig. 13. Growth zone of a deformed vertebra (see box in Fig. 12). Typical osteogenic tissue with osteoblasts and osteoid (Zone A) blends through an intermediate zone (Zone B) into chondrogenic tissue (Zone C) towards the intervertebral space. Fibrocartilage is characterized by linearly arranged isogenic groups of cartilage cells (black arrowheads) and collagen fibre bundles (white arrowheads). Bone tissue contains enclosed osteocytes (black arrows). Scale bar $=50 \mu \mathrm{m}$. Fig. 14. Regular bone (Zone A) and intervertebral cartilage (Zone C) adjoining the bone

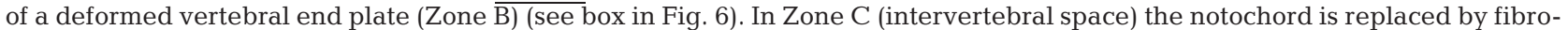
cartilage (white asterisk) that blends into hyaline cartilage with isogenic groups of chondrocytes (black arrowhead). Cartilage mineralizes (white arrowhead) at the border to the bone of the vertebral end plate (Zone B). Bone contains transversely directed collagen fibre bundles (black arrow). Masson's trichrome staining; scale bar $=50 \mu \mathrm{m}$. Fig. 15. Higher magnification of the cartilaginous tissue that replaces the notochord in the intervertebral space with different types of cartilage present: hyaline cartilage with chondrocytes arranged in isogenic groups (black arrowheads), mineralizing hyaline cartilage (black arrow), fibrocartilage (white asterisk), mineralizing fibrocartilage (white arrowhead), and connective tissue (black asterisk). Bone tissue labeled by a black cross. Masson's trichrome staining; scale bar $=80 \mu \mathrm{m}$. Fig. 16. Tissue composition of the vertebral growth zone of adjacent undeformed and deformed vertebrae. In undeformed vertebrae, growth zones of adjacent vertebrae are separated by the notochordal sheath and the skeletogenic tissue only produces bone. Direction of bone formation (black arrows) provides both increase in length and height. In deformed vertebrae, skeletogenic tissues of adjacent vertebrae fuse and are not separated by the notochordal sheath. United tissues give rise to bone and to various types of cartilage towards the intervertebral space. Fusion of the skeletogenic zones from adjacent vertebrae and the altered direction of skeletogenesis apparently changes the direction of vertebral growth (black arrows). We hypothesize that the formation of skeletal tissue only increases the vertebral height but does not support the increase in length

a tendency to mineralize (Fig. 15). The pronounced shape alterations and histological differences between undeformed and deformed vertebral bodies are not reflected by changes in the bone mineral composition (Table 2). The amount of phosphorus and calcium is identical in both groups, and none of the differences obtained for minor mineral components appears to be significant (all p-values $>0.05$ ).

No indication of inflammatory processes were observed, i.e. the presence of lymphocytes, granulocytes, monocytes, or macrophages.

\section{DISCUSSION}

The present group of 'short tail' salmon is characterized by homogeneously compressed vertebrae throughout the spine. No further pathological alterations were observed to accompany the compression of vertebrae. This is in contrast to previous studies reporting vertebral compression (also referred to as platyspondyly) affecting parts of the backbone and coinciding with additional alterations such as fractures, fusion, shift in position, underdevelopment, and torsion of vertebrae. A connection between vertebral deformities and bacterial infections has also been suggested (Madsen \& Daalsgard 1999, Kvellestad et al. 2000, Madsen et al. 2000). In view of multiple alterations that often coincide with vertebral compression, it appears reasonable to assume a complex aetiology for spinal deformities (Vågsholm
\& Djupvik 1998, Madsen \& Daalsgard 1999). Still, one could speculate about a single primary event that leads to various secondary alterations, ultimately being observed as different skeletal malformations. Solving the riddle requires the reconstruction of the animals' developmental history, a difficult task in the practice of aquaculture and wildlife studies. If a fish is sacrificed early for pathological analysis, it may be impossible to determine what type of skeletal deformity the animal will develop later. On the other hand, fish with evident skeletal deformations usually represent an advanced stage of the disease and, as discussed above, display various symptoms. The adult 'short tail' salmon in this study displayed only one type of skeletal malformation, thus offering a 'diagnostic-advantage' in reconstructing the aetiology of compressed vertebrae.

Table 2. Salmo salar. Average vertebral mineral content $( \pm \mathrm{SD})$. N: normal individuals; ST: 'short tails'. All p-values are above 0.05, suggesting that the observed differences are not significant

\begin{tabular}{|llcr|}
\hline & & Average $\left(\mathrm{mg} \mathrm{kg}^{-1}\right.$ ash $)$ & $\pm \mathrm{SD}$ \\
\hline $\mathrm{P}$ & $\mathrm{N}$ & 196641 & 8514 \\
& $\mathrm{ST}$ & 195932 & 4068 \\
$\mathrm{Ca}$ & $\mathrm{N}$ & 387093 & 14120 \\
& $\mathrm{ST}$ & 390166 & 7902 \\
$\mathrm{Mg}$ & $\mathrm{N}$ & 5569 & 342 \\
& $\mathrm{ST}$ & 5637 & 276 \\
\hline
\end{tabular}


Our observations suggest that vertebral compression is related to alterations of the growth zones, as outlined in Fig. 16. Mirror-image growth zones of articulating undeformed vertebrae, separated by the notochordal sheath, give rise to bone in a distinct direction (see also Fig. 11) increasing both the vertebral length and height. In 'short tails', skeletogenic areas of adjacent vertebrae have fused and are not separated by the notochordal sheath (see also Fig. 12). Skeletogenic tissues now give rise to bone and to various types of cartilage that connect the vertebral end plates (synchondrosis). Fusion of the skeletogenic zones and the altered direction of skeletal tissue formation solely enlarge the vertebral height.

The fact that central parts of compressed vertebrae still contain notochordal tissue and regularly shaped vertebral end plates (Fig. 7) strongly suggests that this type of deformity is a late ontogenetic malformation. How late in ontogeny deformities develop in 'short tails' is illustrated by the fact that vertebrae with a height of $0.75 \mathrm{~mm}$ already have the adult shape and structure (Grotmol et al. 2003). Changes in 'short tails' apparently occur only after the vertebrae have reached a height of $5 \mathrm{~mm}$ (Figs. $7 \&$ 8). However, the question remains what could have caused this disorder.

The 'short tails' studied here differ from deformed fish analyzed by Kvellestad et al. (2000) and Madsen et al. (2000) in showing no signs of infections or apoptotic cell death. This suggests that vertebral compressions are not related to acute inflammatory processes. Furthermore, no signs of vertebral fractures reported from Oncorhynchus mykiss in connection to a lack of vitamin-C (Dabrowski et al. 1990) have been observed. In addition, the correspondence between bone mineral contents in undeformed and deformed fish indicates that deformed individuals do not suffer from a disorder of the mineral metabolism. This conclusion is supported by the morphology of the intravertebral spongiosa. Mobilization of bone minerals in teleosts with osteocyte-containing bone (the bone type of salmon) is largely performed by giant multinucleated bone resorbing cells (osteoclasts) that erode the bone surface (Huysseune 2000, Witten et al. 2000, 2001, Witten \& Hall 2002). Thus, smooth (non-eroded) endosteal bone surfaces in deformed fish and the lack of osteoclasts (Fig. 10) are further evidence that the fish do not mobilize bone minerals from their skeleton (Witten \& Hall 2003).

Genetic factors have also been discussed as causes of bone malformations. Triploid salmon, for example, are known to show a high incidence of skeletal deformities (Sadler et al. 2000, Benfey 2001). Also, the uniformity of compressed vertebrae hints at the possibility of genetic factors as the cause of the development of 'short tails'. The studied fish group is, however, not triploid. In general, one would also expect genetic factors to cause developmental disorders at much earlier life stages. Still, one cannot rule out the possibility that some fish are genetically predisposed and develop vertebral compression as a reaction to external cues. As we know from studies on wild salmon the salmon skeleton is reactive to external cues (Kacem et al. 1998, Persson et al. 1998, Witten \& Hall 2003).

Having raised arguments against infectious, metabolic and genetic disorders as the causative agents for the 'short tail' phenotype, the question remains what can trigger the late development of uniformly compressed vertebrae. As we will discuss below, alterations of the vertebral growth zones and vertebral compressions could relate to changes of the notochord tissue.

As a reaction to mechanical force, notochord cells can initiate the conversion of the notochord, and the surrounding notochordal sheath, into cartilage (Lotz et al. 2002). We propose that a metaplasia (notochordal tissue converting into cartilage), possibly as a result of an altered mechanical load regime, leads to alteration of the vertebral shape. Degeneration of the mammalian intervertebral disk is thought to be connected to the impact of elevated mechanical load, either as continuous overexertion or short-term overload (Prescher 1998, Lotz et al. 2002, Oegema 2002). However, as pointed out by Lotz et al. (2002) not all mechanical forces have a negative impact on the intervertebral tissue. As with bone (Witten \& Hall 2003), a certain amount of mechanical load is required to maintain the integrity of the intervertebral disk (Lotz et al. 2002).

A striking feature of compressed salmon vertebrae is the coincidence of metaplastic synchondrosis and the shape alterations of the vertebral end plates, raising the possibility that either bone alterations induce the conversion of the notochord tissue or that changes of the notochord induce bone alterations. The current state of knowledge suggests the latter, since the notochord plays an important role in the induction of vertebral formation and in maintaining vertebral morphogenesis and growth (Patt \& Patt 1969, Hall 1977, 2005, Hunter et al. 2003, Smits \& Lefebvre 2003). It is well established that the spinal cord is responsible for the morphogenesis of vertebral neural arches and the notochord for morphogenesis of the vertebral centra in avian and both anuran and urodele amphibian embryos. Remove the spinal cord and the neural arches form as a continuous block of cartilage, although the vertebral centra develop as normally segmented structures. Remove the notochord and the centra form as a continuous block of cartilage, although the neural arches develop as normally segmented structures (Holtzer 1951, Strudel 1953a,b, 
1955, Detwiler \& Holtzer 1956, and see the discussions in Hall 1977, 2005). Furthermore Lash (1968) provided evidence that the spinal cord helps to remodel the vertebral column as it grows in vivo, thereby preventing compression of the spinal cord. The potential roles for spinal cord and notochord are thus considerable, although little experimental information is available for fish.

Not only can the notochord affect the morphology of the vertebral column, but compression of vertebrae has been linked to the failure of notochord cells to maintain proper vertebral development (Hall 1977, 2005, Oegema 2002). In vertebrate species with limited growth (e.g. humans) the notochord ceases its regulating role for vertebral development as part of the normal ontogeny, followed by the transformation of notochord tissue into cartilage and fibrocartilage (Oegema 2002, Hunter et al. 2003). In salmon, however, the notochord should fulfil its regulating role for vertebral body differentiation throughout life, since salmon and other fish species do not stop growing (Witten et al. 2001).

Transformation of notochordal tissue into cartilage has only been reported in ageing fish (Schaffer 1930). However, in the present study the 'short tails' are not older than 2 yr. Following this line of thought, alterations of the notochord tissue precede alterations of bone morphology, likely through the interruption of notochord cell function, which is to maintain proper vertebral growth. Remarkably, mineralization of the 'new' intervertebral cartilage occurs in 'short tails' (Figs. 7 \& 15). This process could well continue in long living salmon, finally leading to the frequently documented fusion of vertebrae (Madsen \& Daalsgard 1999, Gavaia et al. 2002, Roy et al. 2004).

In conclusion, given the lack of evidence for infections, metabolic and genetic disorders, we propose that an altered mechanical load could have caused the transformation of the bone growth zones in the 'short tails' studied here, and the concomitant replacement of the intervertebral (notochord) tissue by cartilaginous tissues. This hypothesis is supported by the role that notochord cells are known to play in vertebral development and for maintaining the integrity of the intervertebral disk (Patt \& Patt 1969, Hall 1977, 2004, Lotz et al. 2002, Hunter et al. 2003, Smits \& Lefebvre 2003). Whether excessive short-term pressure (Kihara et al. 2002), long-term mechanical overexertion, or even disuse (Lotz et al. 2002) could have damaged the intervertebral tissue under farming conditions remains to be clarified. One can, however, assume that the fishes' swimming activity under farming conditions is limited compared to natural conditions and therefore disuse might indeed play a role. At the same time, farmed fish build up a high muscle mass and generate extreme forces due to acute handling such as grading, vaccination, and pumping for being transported. Thus, a combination of both factors, disuse and mechanical overload might contribute to the development of the 'short tail' phenotype.

Acknowledgements: The authors thank S. Kildal and the staff at Marine Harvest Rogaland (Norway), for supporting this study. P.E.W. and B.K.H. are grateful for funding granted from the Canadian German Science and Technology Cooperation. P.E.W. thanks the 'Deutsche Forschungsgemeinschaft' for supporting studies on salmon bone. B.K.H. thanks NSERC for ongoing support of studies on skeletal development.

\section{LITERATURE CITED}

AOAC International (1995) Official methods of analysis of AOAC International, 16th edn. Association of Official Analytical Chemists, Arlington, VA

Bæverfjord G, Åsgård T, Gjerde B, Holmefjord I, Storset A (1996) Ryggdeformitet hos laks skuldast ikkje innavl eller genfeil. Nor Fiskeoppdrett 10:34-35

Benfey TJ (2001) Use of sterile triploid Atlantic salmon (Salmo salar L.) for aquaculture in New Brunswick, Canada. ICES J Mar Sci 58:525-529

Bucke D, Watermann B (1988) Effects of pollution on fish. In: Salomons W, Bayne BL, Duursma EK, Förster U (eds) Pollution of the North Sea: an Assessment. Springer-Verlag, Berlin, p 612-623

Dabrowski K, El-Fiky N, Köck G, Frigg M, Wieser W (1990) Requirement and utilization of ascorbic acid and ascorbic sulfate in juvenile rainbow trout. Aquaculture 91:317-337

Dedi J, Takeuchi T, Seikai T, Watanabe T (1995) Hypervitamitosis and safe levels of vitamin for larval flounder (Paralichthys olivaceus) fed Artemia nauplii. Aquaculture 133: 135-146

Detwiler SR, Holtzer H (1956) The developmental dependence of the vertebral column upon the spinal cord in the urodeles. J Exp Zool 132:299-310

Gavaia PJ, Dinis MT, Cancela ML (2002) Osteological development and abnormalities of the vertebral colum and caudal skeleton in larval and juvenile stages of hatcheryreared Senegal sole (Solea senegalensis). Aquaculture 211:305-323

Gill CD, Fisk DM (1966) Vertebral abnormalities in sockeye, pink and chum salmon. Trans Am Fish Soc 95:177-182

Grotmol S, Kryvi H, NordvikK, Totland GK (2003) Notochord segmentation may lay down the pathway for the development of the vertebral bodies in the Atlantic salmon. Anat Embryol 207:263-272

Hall BK (1977) Chondrogenesis of the somitic mesoderm. Adv Anat Embryol Cell Biol 53(4):1-50

Hall BK (2005) Bones and cartilage: developmental skeletal biology. Elsevier, London

Holtzer H (1951) Morphogenetic influence of the spinal cord on the axial skeleton and musculature. Anat Rec 109: 373-374

Hunter CJ, Matyas JR, Duncan NA (2003) The threedimensional architecture of the notochordal nucleus pulposus: novel observations on cell structures in the canine intervertebral disc. J Anat 202:279-291

Huysseune A (2000) Skeletal system. In: Ostrander GK (ed) The laboratory fish, Part 4. Microscopic functional anatomy. Academic Press, San Diego, CA, p 307-317 
Kacem A, Meunier FJ, Baglinière JL (1998) A quantitative study of morphological and histological changes in the skeleton of Salmo salar during its anadromous migration. J Fish Biol 53:1096-1109

Kihara M, Ogatab S, Kawano N, Kubota I, Yamaguchi R (2002) Lordosis induction in juvenile red sea bream, Pagrus major, by high swimming activity. Aquaculture 212:149-158

Kvellestad A, Høie S, Thorud K, Tørud B, Lyngøy A (2000) Plathyspondyly and shortness of vertebral column in farmed Atlantic salmon Salmo salar in Norway - description and interpretation of pathologic changes. Dis Aquat Org 39:97-108

Lash JW (1968) Somite mesenchyme and its response to cartilage induction. In: Fleischmajer R, Billingham RE (eds) Epithelial-mesenchymal interactions. Williams \& Wilkins, Baltimore, MD, p 65-172

Lotz JC, Hsieh AH, Walsh AL, Palmer EI, Chin JR (2002) Mechanobiology of the intervertebral disc. Biochem Soc Trans 30(6):853-858

Madsen L, Dalsgaard I (1999) Vertebral column deformities in farmed rainbow trout (Oncorhynchus mykiss). Aquaculture 171:41-48

Madsen L, Arnberg J, Dalsgaard I (2000) Spinal deformities in triploid all-female rainbow trout (Oncorhynchus mykiss). Bull Eur Assoc Fish Pathol 20:206-208

Madsen L, Arnberg J, Dalsgaard I (2001) Radiological examination of the spinal column in farmed rainbow trout Oncorhynchus mykiss (Walbaum): experiments with Flavobacterium psychrophilum and oxytetracycline Aquac Res 32:235-241

McKay LR, Gjerde B (1986) Genetic variation for a spinal deformity in Atlantic salmon, Salmo salar. Aquaculture 52: 263-272

Oegema TR (2002) The role of disc cell heterogeneity in determining disc biochemistry: a speculation. Biochem Soc Trans 30(6):839-844

Patt DI, Patt GR (1969) Comparative vertebrate histology. Harper \& Row Publishers, New York, NY

Persson P, Sundell K, Björnsson BT, Lundqvist H (1998) Calcium metabolism and osmoregulation during sexual maturation of river running Atlantic salmon. J Fish Biol 52: 334-349

Prescher A (1998) Anatomy and pathology of the aging spine. Eur J Radiol 27:181-195

Roy PK, Witten PE, Hall BK, Lall SP (2004) Effects of dietary phosphorus on bone growth and mineralisation of vertebrae in haddock (Melanogrammus aeglefinus L.). Fish Physiol Biochem 2002/27:35-48

Sadler J, Pankhurst PM, King HR (2000) High prevalence of skeletal deformity and reduced gill surface area in triploid Atlantic salmon (Salmo salar L.). Aquaculture 198:369-386

Editorial responsibility: Carl Schreck,

Corvallis, Oregon, USA
Schaffer J (1930) Die Stützgewebe. In: von Möllendorf W (ed) Handbuch der mikroskopischen Anatomie des Menschen, zweiter Teil. Julius Springer Verlag, Berlin, p 1-54

Scott D (2001) Chemical pollution as a factor affecting the sea survival of Atlantic salmon, Salmo salar L. Fish Manage Ecol 8:487-499

Smits P, Lefebvre V (2003) Sox5 and Sox6 are required for notochord extracellular matrix sheath formation, notochord cell survival and development of the nucleus pulposus of intervertebral discs. Development (Camb) 30: $1135-1148$

Strudel G (1953a) Conséquences de l'excision de tronçons du tube nerveux sur la morphogenèse de l'embryon de poulet et sur la différenciation de ses organes: contribution à la genèse de l'orthosympathique. Ann Sci Nat Zool Biol Anim 15 (11):251-329

Strudel G (1953b) Influence morphogène du tube nerveux et de la corde sur la différenciation de la colonne vertébrale. C R Séances Soc Biol Fil 47:132-133

Strudel G (1955) L'action morphogène du tube nerveux et de la corde sur la différenciation des vertèbres et des muscles vertébraux chez l'embryon de Poulet. Arch Anat Microsc Morphol Exp 44:209-235

Taussky HH, Shorr E (1953) A microcolorimetric method for the determination of inorganic phosphorus. J Biol Chem 202:675-685

Toften H, Jobling M (1996) Development of spinal deformities in Atlantic salmon and Arctic charr fed diets supplemented with oxytetracycline. J Fish Biol 49:668-677

Vågsholm I, Djupvik HO (1998) Risk factors for spinal deformities in Atlantic salmon, Salmo salar L. J Fish Dis 21: $47-53$

Witten PE, Hall BK (2002) Differentiation and growth of kype skeletal tissues in anadromous male Atlantic Salmon (Salmo salar). Int J Dev Biol 46:719-730

Witten PE, Hall BK (2003) Seasonal changes in the lower jaw skeleton in male Atlantic salmon (Salmo salar L.): remodelling and regression of the kype after spawning. J Anat 203:435-450

Witten PE, Villwock W, Renwrantz L (1998) Haematogram of the Tilapia Oreochromis niloticus (Cichlidae, Teleostei) and application of a putative phenoloxidase for differentiation between neutrophilic granulocytes and monocytes. Can J Zool 76:310-319

Witten PE, Villwock W, Peters N, Hall BK (2000) Bone resorption and bone remodeling in juvenile carp (Cyprinus carpio). J Appl Ichthyol 16:254-261

Witten PE, Hansen A, Hall BK (2001) Features of mono and multinucleated bone resorbing cells of the zebrafish Danio rerio and their contribution to skeletal development, remodeling and growth. J Morphol 250:197-207

Submitted: March 24, 2004; Accepted: November 16, 2004 Proofs received from author(s): May 4, 2005 